\title{
The Role of Management Skills in the Selection of Management Model by Sports Managers
}

\author{
Rasool Nazari*
}

Faculty of Physical Education and Sport Sciences, Isfahan (Khorasgan) Branch, Islamic Azad University, Isfahan, Iran.

\begin{abstract}
Background. Despite the research being accomplished so far, there is no clear answer to the question that "Do management skills have effect in the selection of management model by sports managers". Objective(s). The present study aims to investigate the effect of technical, human, perceptual, and political skills on the selection of managerial model by sports managers. Methods. This is a descriptive-correlational study conducted using a survey method. The statistical population of the study comprised 405 managers of sport organizations, including managers of general directorate, sports departments, and other organs of Isfahan, of whom 199 individuals were selected with stratified random sampling as the statistical sample through Cochran's sample size formula. The Bass Management Model (1996) and Management Skills of Nazari (2015) were used as the instruments and their face and content validity and reliability were confirmed $(0.91, \alpha=0.89)$. Results. Based on the results of this research, among management skills, managers' perceptual skills can predict power and explain changes in management styles of managers and can explain 39\% of the variance of the managers' management styles. Based on Friedman's test, prioritization of the dimensions of management skills from the managers' point of view indicates that the perceptual skills (3.9) and political skills (2.1) respectively account for the highest and the lowest rank among the studied dimensions. Conclusion. Understanding the general problems of the organization helps managers to be more careful in selecting their styles and choosing the best management model. Although technical knowledge and human and political skills play a significant role, perceptual skills have the most effective role.
\end{abstract}

KEY WORDS: Technical Skill, Perceptual Skill, Human Skill, Political Skill, Transformational Model, Structural Model, Indifferent Model, Sport Managers.

\section{INTRODUCTION}

The environment of today's organizations confronts managers with new challenges and is getting more dynamic every day. New managerial needs arise due to global competition and the developing expectations of societies. An efficient and effective management model is required in this regard for the success of organizations - both manufacturing and service organizations - such that adequate attention is paid to exploring the structures of the management model in the dynamic organizations (1). The structural and transformational managerial models, along with the passive or avoidance management model, create a new model that helps to understand the high and low degrees of management styles. This model is

*. Corresponding Author:

Rasool Nazari

E-mail: nazarirasool@yahoo.com 
based on the authoritarian, democratic, or imperative and participatory paradigm (2). Investigation on the new structures of management model reveals that new styles have the most influence among the leadership with regard to adapting to changes and developments in organizations. Managers select the management model in order to gain the most influence as a leader. Proper selection of the management style, tailored to the external motivation, can help to achieve the goals of the group and the leaders of the organization (3). In this line, sport organizations involved in the sports development are no exception; they also need efficient managers and leaders (4). By adopting various management styles, managers can facilitate the achievement of goals, enhance the sense of happiness and job satisfaction of employees, increase initiatives, and ultimately support the internal and external organizational processes to achieve organizational goals and therefore increase organizational effectiveness. Simulation scenarios, reflective exercises, and role-playing may be useful to facilitate the choice of constructive conflict-management styles (5). Awareness of management knowledge is essential for sports managers to better manage affairs and the assigned duties, since management is the most significant and influential factor in the development of sports and the attainment of goals. In fact, sport management alike all scientific management trends, which is explained by benefiting from the frameworks of management science (6).

Regardless of the nature of the job, organizations today need to be properly and effectively directed toward achieving specific purposes. Thus, like other organizations, sports organizations need competent and effective managers. Global efforts have been made to introduce and train specialized and committed sports managers (7). Moreover, the prioritization of managerial skills is one of the main challenges in senior management, especially in sports organizations (8). For effectiveness and efficiency, in addition to knowledge, managers should have special skills-namely technical, human, perceptual, and political skills. Technical skill refers to the ability to apply knowledge, method, and technique of the means required to perform certain tasks through experience, education, and training. Human skill refers to the judgment required to work with people, along with the awareness of encouragement techniques and use of an effective management model. Perceptual skill refers to the ability to understand the general problems of the organization and identify the section of the organization in which a person is best fitted to work. Such knowledge allows the person to act based on the goals of the entire organization, rather than the goals and needs of one's own group (9). Finally, political skill refers to the ability to effectively understand others in the workplace and employ such knowledge to influence others and to take measures to promote organizational or personal goals (10). In other words, managers with special skills such as technical, human, conceptual, political, and social skills, social intelligence, emotional intelligence, egoresiliency, social self-efficacy, self-monitoring, practical intelligence, creative skills, adversity skills, and spiritual skills are needed for building and maintaining an effective organization. Because performance is important for career advancement, the model gives a potential explanation of why toxic individuals may get ahead at work (11). Results indicate that there is a significant relationship between the adversity quotient and occupational stress. Meanwhile, the role of long-term and strategic goals and awareness of rules and regulations in perceptual skills, effective relationship in human skills, and the delegation of authority in technical skills have the highest priority in managerial skills, in that order (12).

Efficient and effective management, combined with human and material resources, can take effective measures to improve and solve the organization's problems and issues in the current era, where organizations often face major challenges in the field of production and services due to severe economic crises. Undoubtedly, organizations lacking proper workforce and adequate material and financial resources will fail to compete with other organizations if they do not have guidance and management. Management will also lead to a progressive movement and enhancement of performance at different organizational levels in order to overcome the organizational deficiencies with regard to the required skills and abilities, which 
are undoubtedly prerequisite to management (13). Accordingly, in order to lay the groundwork for becoming more efficient, managers often need to understand managerial skills. The most famous theories on managerial efficiency conclude that an efficient manager should be an expert in four skills-namely, technical skill, perceptual skill, human skill, and political skill. Thus, managers need to properly recognize the dynamics of turbulent environments; the efficiency and effectiveness of managers' performance requires the use of managerial skills (14). Hosseinpour et al. (2014) investigated the effect of managerial skills (technical, human, and perceptual skills) of managers on effective effectiveness in their research (15). Moreover, several factors, such as the education level and the approach of individuals, play a role in improving organizational skills (16).

Understanding the management process is essential for managers, considering that management affects the performance of the group and sports organizations. Management determines the success of sports organizations because managers play the most important role in setting strategies that focus on the future; their task is to navigate the direction of the organization. Therefore, it is deemed necessary to recognize managerial models, managerial skills (technical, perceptual, human, and political skills), and the necessity of these skills for a successful manager. Moreover, it may be acknowledged that selecting an appropriate managerial model to guide sport organizations affects the achievement of goals and plans of the sports organizations. Thus, the main question of the research is: "What is the contribution of technical, human, perceptual, and political skills in the selection of the managerial model by managers?"

\section{MATERIALS AND METHODS}

Method. This is a descriptive-correlational study conducted using a survey method.

Participants. As shown in Table 1, the statistical population of the study comprises 405 sports managers, including all managers of Isfahan sport organizations (Isfahan Sports and Youth Department, boards, sports clubs, physical education managers of General Education Office, six districts, and physical education departments of universities). Of these 405, a total of 199 people were selected though stratified random sampling method using the Cochran sampling method.

Table 1. Statistical population and statistical sample categorized by organization

\begin{tabular}{lcc}
\hline \multicolumn{1}{c}{ Organizational position } & Statistical population & Statistical Sample \\
\hline Isfahan Sports and Youth Departments & 55 & 27 \\
Isfahan General Education Office and districts & 50 & 25 \\
Universities & 25 & 12 \\
Sports and cultural clubs & 25 & 12 \\
The sports boards & 250 & 123 \\
Total population of the statistical population & 405 & 199 \\
\hline
\end{tabular}

Research Tools. Measurement is done using the Bass et al. (1996) Management Model questionnaires (17), with three componentstransformational, structural, and indifferent managerial models - and Nazari (2015) management skills (18), with four componentsperceptual, human, technical, and political . The five-point Likert scale was used to answer questions in which "totally disagree" was assigned with the lowest score (1) and "totally agree" with the highest score (5). To determine the face and content validity of the questionnaires used in the present research, the author consulted with 10 faculty members in sport management. The questionnaires were approved after implementing their comments. The split-half method and Cronbach's alpha test were used to measure reliability. For this purpose, the questionnaires were distributed in the form of a pilot study; this value was calculated based on the data obtained from the communication skills questionnaire $(\alpha=0.91)$ 
and management models $(\alpha=0.89)$, indicating that the used questionnaires have the required reliability.

Statistical Analysis. In the present study, the data were analyzed using descriptive statistics (percentage of frequency, mean, and standard deviation), inferential statistics, regression test, pairwise t-test, and Friedman test. All data were analyzed using SPSS version 22.

\section{RESULTS}

The results of the descriptive statistics of gender indicate that approximately $31 \%$ of the subjects were women and approximately $69 \%$ were men. The Kolmogorov-Smirnov test was used for investigating the normality of the sample and Levin test was used for testing variance homogeneity $(p>0.05)$. According to the obtained results, the statistical sample of the study has a normal distribution and study variables have variance homogeneity.

The author has used regression to determine the effect of the managerial skills components on the selection of managerial model by sports managers. According to results of analysis of variance and statistical characteristics of regression between the components of managerial skills and the management model, approximately $39 \%$ of the variance related to the management model is explained by the components of management skills $\left(\mathrm{R}^{2}=0.39\right)$, which means that $39 \%$ of the selection of management model is predicted by managerial skills (Table 2).

Table 2. Characteristics of regression

\begin{tabular}{ccc}
\hline Index & $\boldsymbol{R}$ & $\boldsymbol{R}^{2}$ \\
\hline Regression & 0.63 & 0.39 \\
\hline
\end{tabular}

Considering the results shown in Table 3, the level of significance implies that there is a significant relationship between predictor variables and the criterion in this model. This relationship is significant at the level of 0.05 ; i.e. there is a linear relationship between the components of management skills and management model $(\mathrm{p}=0.001)$.

Table 3. Summary of Analysis of Variance

\begin{tabular}{cccccc}
\hline Index & SS & DF & Mean Square & F & P \\
\hline Regression & 21.63 & 4 & 5.41 & & \\
Residual & 33.10 & 157 & & 25.65 & 0.001 \\
Total & 54.74 & 161 & 0.211 & & \\
\hline
\end{tabular}

According to the results of multivariate regression (Table 4$)$, the perceptual skills $(\mathrm{p}=$ 0.04, $\mathrm{t}=2.02)$, technical skills $(\mathrm{p}=0.04, \mathrm{t}=$ $1.92)$, human skills $(\mathrm{p}=0.44, \mathrm{t}=1.81)$, and political skills $(\mathrm{p}=0.4, \mathrm{t}=1.72)$ are qualified for predicting management models. Also, the results of regression line slope (B) on the predictor variables indicate that there is a direct relationship between them. The beta criterion factor $(\beta)$ is also applied as a measure of the relative importance of the variables.

Thus, the regression equation between the components of management skills and management model is as follows:
Management Model $=1.90+0.18$ (Perceptual Skills) + 0.16 (Human Skills) + 0.17 (Technical Skills) + 0.12 (Political Skills)

There is a significant difference between the dimensions of management skills $(\mathrm{p}<0.001$ and $X^{2}=734.5$ ). Prioritizing the dimensions of managerial skills from the managers' point of view indicates that the perceptual skill (3.98) has the highest rank and the political skill has the lowest rank (2.1) among the studied dimensions (Table 5).

According to the findings shown in Table 6, considering the difference between demographic characteristics and management skills, the paired 
t-test results based on gender differences indicate that there is no significant relationship between the components of management skills and gender.

Table 4. Summary of regression Table

\begin{tabular}{ccccc}
\hline Index & $\boldsymbol{B}$ & $\boldsymbol{B e t a}$ & $\boldsymbol{t}$ & $\boldsymbol{P}$ \\
\hline Constant factor & 1.90 & - & 11.84 & 0.00 \\
Perceptual skills & 0.18 & 0.27 & 2.02 & 0.04 \\
Human skills & 0.16 & 0.23 & 1.81 & 0.044 \\
Technical skills & 0.17 & 0.28 & 1.92 & 0.04 \\
Political skills & 0.12 & 0.16 & 1.72 & 0.048 \\
\hline
\end{tabular}

Table 5. Friedman test to determine the difference and prioritize the dimensions of managerial skills

\begin{tabular}{ccccccc}
\hline No. & Variables & Number & Mean rank & Chi-sq & Degrees of freedom & p \\
\hline $\mathbf{1}$ & Perceptual Skill & 199 & 3.9 & & & \\
$\mathbf{2}$ & Human skill & 199 & 2.8 & 734.5 & 3 & $<0.001$ \\
$\mathbf{3}$ & Technical skill & 199 & 2.6 & & & \\
$\mathbf{4}$ & Political skill & 199 & 2.1 & & & \\
\hline
\end{tabular}

Table 6. Paired t-test for investigating gender and management skills

\begin{tabular}{llllc}
\hline \multicolumn{1}{c}{ Component } & Dimensions & The t- statistics & Degrees of freedom & $\mathbf{p}$ \\
\hline Management skills & Perceptual skills & 0.91 & 160 & 0.36 \\
and & Human skills & -0.32 & 160 & 0.74 \\
Gender & Technical skills & 0.93 & 160 & 0.35 \\
& Political skills & 0.082 & 160 & 0.93 \\
\hline
\end{tabular}

\section{DISCUSSION}

Analyzing the findings reveals that approximately $39 \%$ of the variance related to the management model is determined by the components of management skills, meaning that managerial skills predict $39 \%$ of the management model selection. These results are consistent with the results of Crawford and Strohkirch (2004), Benar et al. (2014), and Kheirmand et al. (2012), who conclude that management skills are related to the effectiveness of the organization. The research results also indicate that among management skills, perceptual skills, technical skills, human skills, and eventually political skills of managers can predict and explain the changes in the selection of managerial model by managers and can account for $39 \%$ of the variance (changes) in managerial model selection $(9,14,19)$. Crawford and Strohkirch (2004 also conclude that perceptual differentiation could be a good predictor of the transformational management model (19). Kheirmand et al. (2012) indicate in their research that first-rate managers have higher perceptual skill and second-rate ones have higher political skills (14). Accordingly, the present research results state that the ability to understand the general problems of the organization and to identify which worker suits what part of an organization motivates managers to be more careful in selecting their management styles and choosing the best managerial model. This is because the role of management models in the effectiveness of the organization and its performance is undeniable and having the knowledge and perceptual skills will contribute to this factor. The present research shows that perceptual, technical, human, and political skills of managers can predict changes in the managerial model of managers. Perceptual skills account for the highest share as they increase the power of understanding mutual effects of different sections of the organization and the ability to analyze organizational issues and problems, in turn affecting the selection of managerial models by sport managers. According to the results, the perceptual skills of managers can lead to changes in managerial 
model selection, as these skills increase the ability to understand the mutual effects of different sections of the organization and the ability to analyze organizational issues and problems, which in turn affects the selection of managerial models by sport managers.

The research results also reveal that the prioritization of managerial skills includes perceptual skill, human skill, technical skill, and political skill, which affect the selection of managerial model by sport managers. Benar et al. (2014) indicate in their research results that four skills-technical, human, perceptual, and political-are important factors for managers. The final model of their research also indicates the high levels of interaction among these skills (9). The results also indicate that while managers need to acquire the four necessary skills and improve them, they are often not able to do this. This is because the high level of interaction of these skills suggests that the existence of a weakness in one skill will reduce the ability to improve other managerial skills. However, based on the results of this study, it can be stated that managers at all organizational levels need managerial skills (perceptual, human, technical and political skills), and the possession of such skills is important in determining effective management models for the organization. Choosing the appropriate management model in the long term is important for the development and survival of an organization. Managers with political, technical, human, perceptual skills and the ability to select appropriate models of management in the organization will increase the participation of employees in the organization; they will always try to strengthen their subordinates and direct them toward achieving organizational goals. It can be said that increasing the amount of managerial skills and managerial knowledge of sports managers can increase their ability to pay attention to the needs of others, enhance their ability to pay attention to work methods that improve the employee's mental dynamics, and help managers to provide new working methods and pay attention to individual differences in the organization. These managerial factors play a crucial role in advancing the goals of organizations; in fact, having these skills will ultimately help to better understand and select the right managerial model. Considering the results of the present study, it can be inferred that by increasing the perceptual skills of managers, the ability to understand the interactions of different sections of the sports organization and the ability to analyze the issues and problems of these organizations in the form of internship classes and pre-service training improves, which in turn paves the groundwork for their perceptual ability for increasing the efficient and appropriate selection of management models.

Based on the research findings, there is no significant difference among the components of managerial skills in terms of gender. This finding confirms the results of Al-Bogami, 2015 (20). Also, Naderian Jahromi and Amir Hosseini (2008) conclude in their study that gender is not significantly related to human skill (6). However, in terms of managerial styles, Mujtaba and Kaifi (2010) do not have consistent results in the managerial skills section (21). Therefore, based on the findings of this study, it can be said that being male or female does not have an effect on the selecting of management model and possession of management skills among managers of sport organizations and that women, like men, can have effective management styles and skills in the field of sports management. It seems that managers at each level perform their specific management tasks with proper quality and skill, have the ability to work with subordinates, understand organizational problems, act in accordance with the objectives of their organization, influence others, and conduct all activities on the basis of political skill in order to achieve either the goals of the organization or their personal goals.

Therefore, it is suggested that increasing the level of technical, human, political, and especially perceptual skill of managers, i.e. increasing the ability to understand the mutual effects of different sections of the organization and to analyze the potential problems and issues of these organizations, lays the groundwork for their perceptual ability to increase the efficiency and appropriately select models. It is suggested that high-rank managers and relevant authorities should choose people who have managerial skills and other proper characteristics for the organization's positions, regardless of the gender. Further, they should select people with 
the transformational managerial model. Therefore, it can be said that higher levels of technical, human, perceptual, and political skills in individuals better enable them to select the management model appropriate to the missions and goals of the organization. Also, having these skills can be effective in selecting the appropriate behavioral models of managers with their subordinates in a sport organization and contribute to the long-term success of the organization.

\section{CONCLUSION}

By and large, in the current world, sports managers can be effective in maintaining and sustaining their sports organizations if they use the right model and have effective managerial skills. Therefore, it can be argued that the managerial model applied in sports organizations by managers is one of the factors affecting the innovation and motivation, creating competition and healthy relationships, and increasing job satisfaction and productivity in organizations. Identifying and reviewing various management models and the issues affecting them are essential. In fact, having these skills will contribute to a better understanding of managerial skills and ultimately help select the correct management model. Finally, high-level managers in the process of selecting managers for sports organizations can use the model presented in this research as a selection and appointment process model for managers.

\section{APPLICABLE REMARKS}

- Sports managers between four management skills should increase the level of political skill.

- The missions and goals of the sports organization are very important to apply the management skills.

- Sports manager must select the correct management style according to management skills.

\section{REFERENCES}

1. Nazari R, Dadkhah I, Yektayar M. The Relationship between communication skills and leadership styles among Isfahan's sport media managers. Communication Management in Sport Media. 2013;1(2):9-13 [Article in Farsi].

2. Avolio BJ, Zhu W, Koh W, Bhatia P. Transformational leadership and organizational commitment: mediating role of psychological empowerment and moderating role of structural distance. Journal of Organizational Behavior. 2004;25(8):951-68.

3. Goodarzi M, Nazari R, Ehsani M. Structural Equation Modeling of the influence of communication skills on Management skills between sport managers. Applied research of Sport Management and Biology. 2012;1(1):1120 [Article in Farsi].

4. Forghani Ozrudi MB, Yaghobi A. The relationship between leadership and responsibility in the executive office of Physical Education in Tehran city. Sport Management Studies. 2015;9(7):151-66 [Article in Farsi].

5. Nazari R, Salehi A. Structural Equation Modeling of the Effect of Communication Skills on Referee Skills and Efficiency in Iran Football Primer League Referees: Presenting a Model. New Trends in Sport Management. 2017;5(16):49-60 [Article in Farsi].

6. Naderian Jahromi M, Amir Hosseini SE. The Study Of Relationship Between Managers Demographic \& Personality Characteristics And Their Occupation Skills. Olympic. 2008;15(4):105-14 [Article in Farsi].

7. Gabriel CG, Alina CI. Research on the Management of Sports Organizations. Procedia - Social and Behavioral Sciences. 2014;140:667-70.

8. Seyedinejat SS, Razaghi ME, Dousti M. Prioritizing managerial skills based on Katz's Theory cast study: The managers of sports and youth in Mazandaran Province. Pamukkale Journal of Sport Sciences. 2014;5(1):33-47.

9. Benar N, Ramezani Nejad R, Surani M, Gohar Rostami H, Yeganehfar N. Designing a Managerial Skills Model for Chief Executive Officers (CEOs) of Professional Sports Clubs in Isfahan Province. ssr. 2014;23(1-2):59-77.

10. Fani AA, Sheikhinejad F, Danaee-fard H, Hasanzadeh A. Investigating the Moderating Effects of Political skill and Political will on the Relationship between Perceptions of Organizational Politics and Political Behavior Case study: Water Industry of Iran. Management Research in Iran. 2014;18(1):193-221 [Article in farsi].

11. Templer KJ. Dark personality, job performance ratings, and the role of political skill: An indication of why toxic people may get ahead at work. Personality and Individual Differences. 2018;124:209-14. 
12. Singh S, Sharma T. Affect of Adversity Quotient on the Occupational Stress of IT Managers in India. Procedia Computer Science. 2017;122:86-93.

13. Afshari M, Honari H, Karegar G. The Relationship between Management Skills and Organizational Learning in Physical Education Organization and Presenting a Model Based on AHP. Journal of Sport Management. 2011;3(11):5-31 [Article in Farsi].

14. Kheirmand M, Lotfi H, Etebarian A. Relationship between Management Skills of Keshavarzi Bank's Branch Managers in Isfahan with the Efficiency of the Branches. Quarterly Journal of Management and Development Process. 2012;25(3):93-119 [Article in Farsi].

15. Hosseinpour M, Tamimi L, Hosseinpour N, Hashami K, Jafarzadeh S. Study the relationship between principals' management skills and their effectiveness in Karaj 4th district primary schools. Journal of Educational and Management Studies. 2014;4(1):113-7.

16. Bikic A, Reichow B, McCauley SA, Ibrahim K, Sukhodolsky DG. Meta-analysis of organizational skills interventions for children and adolescents with Attention-Deficit/Hyperactivity Disorder. Clinical Psychology Review. 2017;52:108-23.

17. Bass BM, Avolio BJ, Atwater L. The Transformational and Transactional Leadership of Men and Women. Applied Psychology. 1996;45(1):5-34.

18. Nazari R, Ghasemi H, Sohrabi Z. The Relationship between Communication Skills, Leadership Styles, Organizational Culture and Managers' Effectiveness in Sports Organizations: Structural Equations Modeling. Journal of Sport Management \& Behavior Movement. 2015;11(21):93-102 [Article in Farsi].

19. Crawford CB, Strohkirch CS. Transformational leaderas person-centered communicator: empirical findings and observations for leadership educators. Journal of Leadership Education. 2004;3(1):40-60.

20. Al-Bogami HMZ. The Relationship between Transformational Management and Communication Skills among Heads of Departments of KAU. Procedia Computer Science. 2015;65:1160-4.

21. Mujtaba B, Kaifi BA. Management Skills of Afghan Respondents: A Comparison of Technical, Human and Conceptual Differences Based on Gender. Journal of International Business and Cultural Studies. 2010;4(1):1-14. 